\title{
Cervical lymph node metastases in salivary gland adenoid cystic carcinoma: a systematic review and meta-analysis
}

This article was published in the following Dove Press journal: Cancer Management and Research

\author{
Chunliu Ning' \\ Tengfei Zhao' \\ Zechen Wang' \\ Delong $\mathrm{Li}^{1}$ \\ Yurong Kou ${ }^{2}$ \\ Shaohui Huang' \\ 'Department of Oral and Maxillofacial \\ Surgery, School of Stomatology, \\ China Medical University, Shenyang, \\ Liaoning, People's Republic of China; \\ ${ }^{2}$ Department of Oral Biology, School \\ of Stomatology, China Medical \\ University, Shenyang, Liaoning, \\ People's Republic of China
}

Background: The purpose of this research was to determine whether neck dissection is necessary for the adenoid cystic carcinoma (ACC) of head and neck.

Materials and methods: This article screened the abstract and full-text papers that investigated salivary gland primary ACC of head and neck. Two independent reviewers searched for articles published before October 2017 in three databases (Web of Science, PubMed, and Ovid), having no limits in date and language. Statistical data were analyzed statistically by Review Manager 5.3. Results: In total, 18 studies involving 2993 patients were included in the analysis. Of the 2993 patients, 473 patients had cervical lymph node metastasis, with a merge frequency of $16 \%$ (95\% CI: 13-19). Among included articles, only 4 involved cervical lymph node occult metastases, with a merge frequency of $14 \%$ (95\% CI: 9-20). There were 5 articles containing minor salivary glands (MiSGs) involving 370 patients of which 92 patients had cervical lymph node metastases and the merge frequency was $25 \%$ (95\% CI: 11-38). Moreover, there were 4 studies on major salivary glands involving 904 patients of which 158 patients had cervical lymph node metastases and the merge frequency was $17 \%$ (95\% CI: 15-20).

Conclusion: Elective neck dissection is unnecessary for all patients with salivary gland ACC of head and neck. Moreover, compared with major salivary glands, MiSGs have a higher cervical lymph node metastases rate in ACC. The overall cervical lymph node metastases rate of MiSGs is $25 \%$, which is enough to attract our attention. Therefore, we suggest that neck dissection might be applied to ACC of MiSGs.

Keywords: adenoid cystic carcinoma, rates of cervical metastases and occult metastases, elective neck dissection, meta-analysis

\section{Introduction}

Adenoid cystic carcinoma (ACC) of the head and neck is an uncommon carcinoma characterized by frequent local recurrence and distant metastasis. Most researchers of ACC have focused on its distant metastases. ${ }^{1}$ Cervical lymph node metastasis has traditionally been regarded as an obviously uncommon occurrence. Increasing researchers have focused on the cervical metastases of ACC in recent years. Primary tumor site, peri-tumoral lymphovascular invasion and $\mathrm{T}$ stage were associated with nodal metastasis. ${ }^{2,3}$ Cervical lymph node metastases has been reported to occur in approximately $4 \%-33 \%$ of patients with ACC. ${ }^{4-7}$ The reasons of large variation in the reported nodal metastasis (4\%-33\%) may be that most studies reported on small patient cohorts and the difference of primary tumor sites. Minor salivary glands (MiSGs) are more often involved and have a higher rate of neck lymph node metastases than major salivary
Correspondence: Shaohui Huang Department of Oral and Maxillofacial Surgery, School of Stomatology, China Medical University, No 1 I 7 Nanjing Bei Jie, Heping District, Shenyang, Liaoning I 10002 , People's Republic of China $\mathrm{Tel} / \mathrm{Fax}+862431927739$

Email huangshaohui@hotmail.com 
glands (MaSGs)., ${ }^{2,7-9}$ Therapeutic neck treatment is usually performed in clinically node positive $(\mathrm{cN}+)$ status. Elective neck treatment is recommended only in specific high-grade tumors and is not generally suggested in all ACCs. However, several recent researches have focused on cervical metastases in ACC, and elective neck treatment (either operation or radiation) has got attention as a viable option., ${ }^{5,10-12}$ The decision regarding an elective neck dissection (END) should be based on the incidence of lymph node metastases. The reports about cervical lymph node metastases rates of ACC are different. Therefore, the aim of this study was to determine whether neck dissection is necessary for the ACC of head and neck by analyzing the frequency of cervical lymph node metastases with meta-analysis.

\section{Materials and methods Search strategy}

We searched Web of Science, PubMed, and Ovid for scientific papers concerning cervical lymph node metastases for ACC. Articles that met the following search strategies in the title, abstract or keywords were included, without regard to language (carcinoma, adenoid cystic OR (carcinoma AND adenoid AND cystic) OR adenoid cystic carcinoma OR (adenoid AND cystic AND carcinoma)) AND (node AND (neoplasm metastasis OR (neoplasm AND metastasis) OR neoplasm metastasis OR metastases) OR neck dissection OR (neck OR dissection)). The latest search was conducted on October 14, 2017, and manual searches in the reference lists of related articles were performed to ensure inclusion of all relevant studies.

\section{Inclusion/exclusion criteria}

The management and repeat deletion of the identified literature were performed using Endnote X7 software. If several literatures were published by the same team, the latest study or study with the largest size was selected for further evaluation.

\section{Inclusion criteria}

1. Researches that investigated the frequency of cervical lymph node metastases in primary salivary gland ACC of head and neck.

2. The researches included data that can be extractable, and cervical lymph node metastases were confirmed by pathology.

\section{Exclusion criteria}

1. Researches on patients who had undergone preoperative radiotherapy and chemotherapy.
2. Researches that only investigated ACC of the upper respiratory or sinonasal.

3. Researches that only investigated clinical cervical metastases in salivary gland ACC.

Single case reports and articles in languages other than English and Chinese were also excluded.

\section{Data extraction and quality assessment}

Data extraction and quality assessment of all included researches were independently performed by 2 authors. Controversies were solved by discussion or consultation with another author. Basic information such as authors, publication year, recruitment years, patient characteristics, total ACC cases, cases of cervical metastases and frequency of metastases, treatments and outcomes were extracted. The quality assessment of each articles was managed using Newcastle-Ottawa Quality Assessment Scale.

\section{Statistical analysis}

Data synthesis and statistical analysis were performed with Review Manager 5.3. Standard error, risk difference and 95\% CI were pooled to analyze the morbidity of cervical lymph node metastases. Chi-squared-based $Q$ test and $I^{2}$ were used for heterogeneity evaluation. The fixed-effect model was used when there was no heterogeneity $\left(P>0.10\right.$ and $\left.I^{2}<50 \%\right)$; the random-effect model was used when there was heterogeneity $\left(P<0.10\right.$ or $\left.I^{2}>50 \%\right)$. Publication bias was evaluated using the Funnel plots.

\section{Results}

We retrieved 544 articles from the database search (Web of Science, PubMed and Ovid), and 3 additional articles were found after reviewing articles and reference lists of retrieved articles and preprint online publications. After removing the duplications, 491 articles were retained. Next, the studies were screened by title and abstract and 51 articles remained. After full-text revision, 33 articles were excluded for various reasons. Thus, 18 articles, all published in English, were included for further investigation. ${ }^{2,3,5,7,13-25}$ The study selection procedure is illustrated by flow diagram (Figure 1). In total, 18 studies involving 2993 patients were included in the analysis. Of the 2993 patients, 473 patients had cervical lymph node metastasis, which were approved by pathologic inspection.

Among 18 included studies, 4 had a relatively low quality and 14 had a high-quality design as found by quality assessment. Detailed information for the included articles is listed in Table 1. Eleven studies only provided total cases 


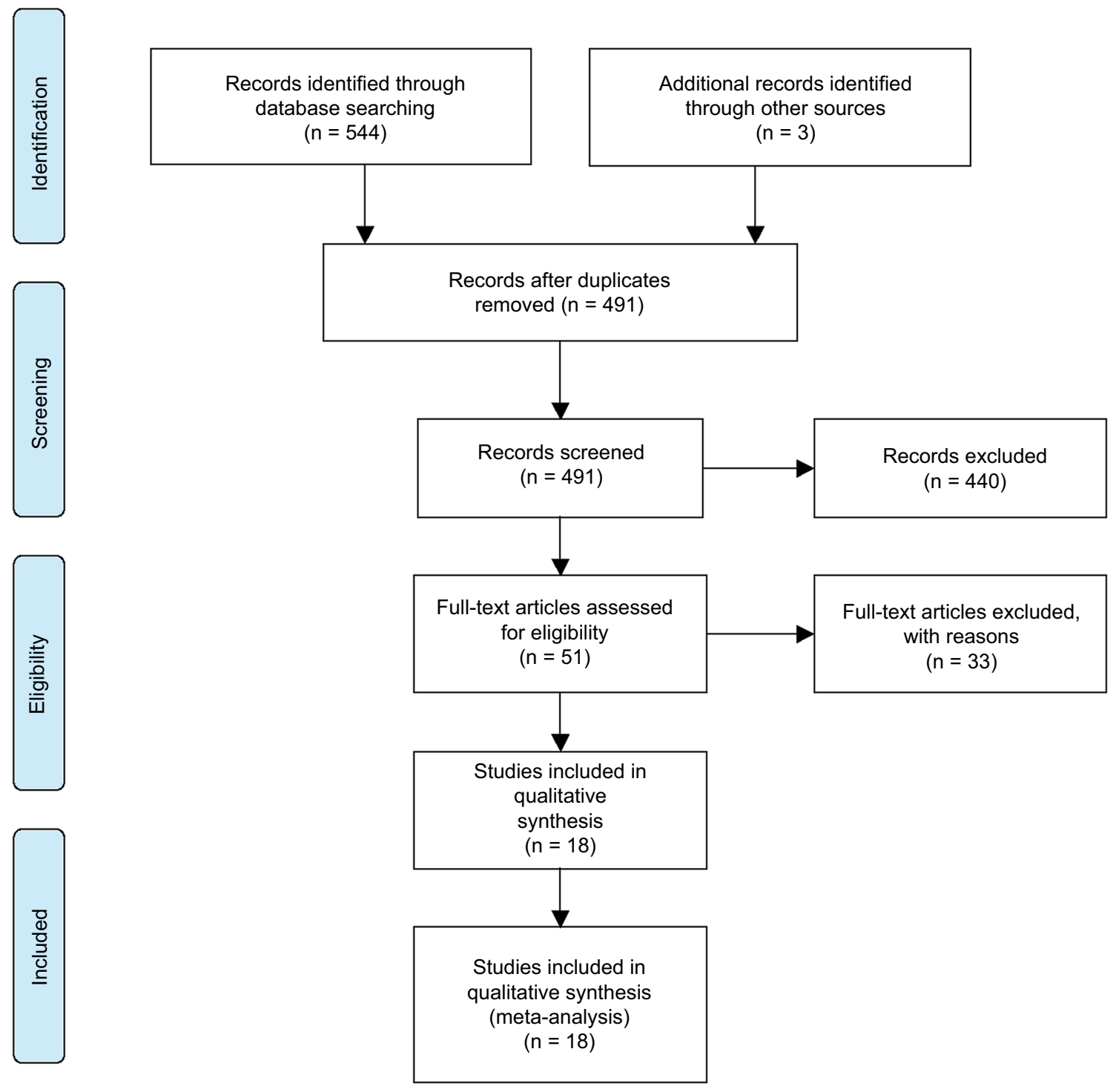

Figure I PRISMA flow diagram for the study selection process.

of patients without the number of patients with neck dissection. Seven studies involved the cases of patients with neck dissection, 4 of which included occult metastases. The overall metastases rate was defined as the ratio between the number of pathological node positive $(\mathrm{pN}+)$ cases and total cases. During the follow-up period, patients without neck dissection initially presenting with regional metastases or recurrence would also be considered as $\mathrm{pN}+$ cases. The occult metastases rate was defined as the ratio between the number of $\mathrm{cN}-\mathrm{pN}+$ cases and total $\mathrm{cN} 0$ cases ${ }^{26}$ Detailed information about occult metastases is listed in Table 2 .

The primary site of inclusion cases in these studies was somewhat inconsistent. Three studies only included MiSGs ACC patients; 2 studies only involved MaSGs ACC patients; and 2 researches provided node metastases cases of MiSGs and MaSGs. The detailed information for primary site of salivary glands was not provided in the rest of researches (11 articles). Detailed information for primary site of salivary glands is listed in Table 3.

\section{Results of the pooled analysis}

The forest plot (or blobbogram) for cervical lymph node overall metastases about ACC showed that the pooled ratio of cervical metastases was $16 \%$ (95\% CI: 13-19) used a random effects model (Figure 2). The relevant Funnel plot revealed that the majority of articles were close to axis and there was no publication bias in these researches (Figure 3).

The forest plot for cervical lymph node occult metastases about ACC indicated that the pooled frequency of occult metastases was 14\% (95\% CI: 9-20) used a random effects 
Table I Information on 18 studies included in the analysis

\begin{tabular}{|c|c|c|c|c|c|c|}
\hline Study & Year & $\begin{array}{l}\text { Recruitment } \\
\text { years }\end{array}$ & $\begin{array}{l}\text { Total ACC } \\
\text { cases }\end{array}$ & $\begin{array}{l}\text { Cases of neck } \\
\text { dissection }\end{array}$ & $\begin{array}{l}\text { Cervical lymph node } \\
\text { metastases }(\mathrm{pN}+)\end{array}$ & $\begin{array}{l}\text { Metastatic } \\
\text { rate, \% }\end{array}$ \\
\hline Bhayani et $\mathrm{al}^{5}$ & 2012 & $1990-2007$ & 30 & 30 & 7 & 23.3 \\
\hline Amit et $\mathrm{al}^{7}$ & 2015 & $|985-20| \mid$ & 270 & 270 & 79 & 29.3 \\
\hline Min et $\mathrm{al}^{2}$ & 2012 & $1995-2009$ & 616 & - & 62 & 10.1 \\
\hline Liu et $\mathrm{al}^{13}$ & 2015 & $2000-2013$ & 272 & 272 & 58 & 21.3 \\
\hline Megwalu and Sirjani ${ }^{3}$ & 2017 & $1988-2013$ & 720 & - & 126 & 17.5 \\
\hline Mücke et $\mathrm{al}^{14}$ & 2010 & $1992-2006$ & 33 & 18 & 8 & 24.2 \\
\hline van Weert et al ${ }^{15}$ & 2013 & 1979-2009 & 105 & - & 11 & 10.5 \\
\hline Jang et $\mathrm{al}^{16}$ & 2017 & $199 \mid-2013$ & 61 & - & 8 & 13.1 \\
\hline Ali et $\mathrm{a}^{17}$ & 2017 & $1985-2009$ & 87 & 30 & 10 & 11.5 \\
\hline Meyers et a $\left.\right|^{18}$ & 2016 & $2009-2012$ & 87 & - & 9 & 10.3 \\
\hline Bjørndal et $\mathrm{a}^{8}$ & 2015 & $1990-2005$ & 71 & - & 12 & 16.9 \\
\hline Ko et a $\left.\right|^{19}$ & 2016 & $2000-2014$ & 60 & - & 7 & 11.7 \\
\hline Hämetoja et $\mathrm{al}^{20}$ & 2017 & $1974-2012$ & 17 & 17 & 4 & 23.5 \\
\hline Mannelli et $\mathrm{a}^{21}$ & 2017 & $1980-2005$ & 44 & - & 8 & 18.2 \\
\hline Ouyang et $\mathrm{a}^{22}$ & 2016 & $1990-2015$ & 228 & - & 21 & 9.2 \\
\hline Zhang et $\mathrm{a}^{23}$ & 2013 & $2000-2007$ & 218 & - & 29 & 13.3 \\
\hline Kruse et $\mathrm{a}^{24}$ & 2010 & 1999-2008 & 13 & - & 3 & 23.1 \\
\hline Lee et $\mathrm{al}^{25}$ & 2014 & $199 \mid-2009$ & 61 & 30 & 11 & 18.0 \\
\hline Total cases & & & 2993 & & 473 & \\
\hline
\end{tabular}

Note: “-”, Data not provided.

Abbreviations: ACC, adenoid cystic carcinoma; $\mathrm{pN}+$, pathological node positive.

Table 2 Articles on occult metastases

\begin{tabular}{|c|c|c|c|c|c|c|c|}
\hline \multirow[t]{2}{*}{ Study } & \multirow[t]{2}{*}{ Year } & \multicolumn{2}{|l|}{$\mathrm{cN}+$} & \multicolumn{2}{|l|}{$\mathbf{c N}-$} & \multirow{2}{*}{$\begin{array}{l}\text { Overall metastatic } \\
\text { rate, } \%\end{array}$} & \multirow{2}{*}{$\begin{array}{l}\text { Occult metastases } \\
\text { rate, } \%\end{array}$} \\
\hline & & Total & $\mathrm{pN}+$ & Total & $\overline{\mathrm{pN}+}$ & & \\
\hline Bhayani et $\mathrm{a}^{5}$ & 2012 & 0 & 0 & 30 & 7 & 23.3 & 23.3 \\
\hline Lee et $\mathrm{a}^{25}$ & 2014 & 4 & 3 & 57 & 8 & 18.0 & 14.0 \\
\hline Amit et $\mathrm{al}^{7}$ & 2015 & 44 & 40 & 226 & 39 & 29.3 & 17.3 \\
\hline Ali et $\mathrm{a}^{17}$ & 2017 & 3 & 3 & 84 & 7 & 11.5 & 8.3 \\
\hline
\end{tabular}

Abbreviations: $\mathrm{cN}+$, clinically node positive; $\mathrm{cN}$-, clinically node negative; $\mathrm{pN}+$, pathological node positive.

Table 3 Information on site of salivary glands

\begin{tabular}{|c|c|c|c|c|c|c|}
\hline \multirow[t]{2}{*}{$\overline{\text { Study }}$} & \multirow[t]{2}{*}{ Year } & \multirow{2}{*}{$\begin{array}{l}\text { Total ACC } \\
\text { cases }\end{array}$} & \multicolumn{2}{|l|}{ Site } & \multirow{2}{*}{$\begin{array}{l}\text { Node metastases } \\
(\mathrm{pN}+) \text { for MiSGs }\end{array}$} & \multirow{2}{*}{$\begin{array}{l}\text { Node metastases } \\
(\mathrm{pN}+) \text { for MaSGs }\end{array}$} \\
\hline & & & MiSGs & $\overline{\text { MaSGs }}$ & & \\
\hline Kruse et $\mathrm{a}^{24}$ & 2010 & 13 & 13 & 0 & 3 & 0 \\
\hline Mücke et al ${ }^{14}$ & 2010 & 33 & 33 & 0 & 8 & 0 \\
\hline Bhayani et $\mathrm{al}^{5}$ & 2012 & 30 & 0 & 30 & 0 & 7 \\
\hline Zhang et $\mathrm{a}^{23}$ & 2013 & 218 & 159 & 59 & 22 & 7 \\
\hline Amit et $\mathrm{al}^{7}$ & 2015 & 270 & 148 & 95 & 55 & 18 \\
\hline Mannelli et $\mathrm{al}^{21}$ & 2017 & 44 & 0 & 44 & 0 & 8 \\
\hline Hämetoja et $\mathrm{a}^{20}$ & 2017 & 17 & 17 & 0 & 4 & - \\
\hline Megwalu and Sirjani ${ }^{3}$ & 2017 & 720 & 0 & 720 & 0 & 126 \\
\hline
\end{tabular}

Abbreviations: ACC, adenoid cystic carcinoma; MiSGs, minor salivary glands; MaSGs, major salivary glands.

model (Figure 4). The corresponding Funnel plot revealed that the majority of articles were close to axis and there was no publication bias in these researches (Figure 5).

The forest plot for cervical lymph node metastases about ACC of MiSGs showed that the pooled rate of cervical metastases was 25\% (95\% CI: 11-38) used a random effects model (Figure 6). The relevant Funnel plot indicated that the majority of articles were close to axis and there was no publication bias in these researches (Figure 7).

The forest plots for cervical lymph node metastases rate about ACC of MaSGs indicated that the pooled frequency of cervical metastases was 17\% (95\% CI: 15-20) used a 


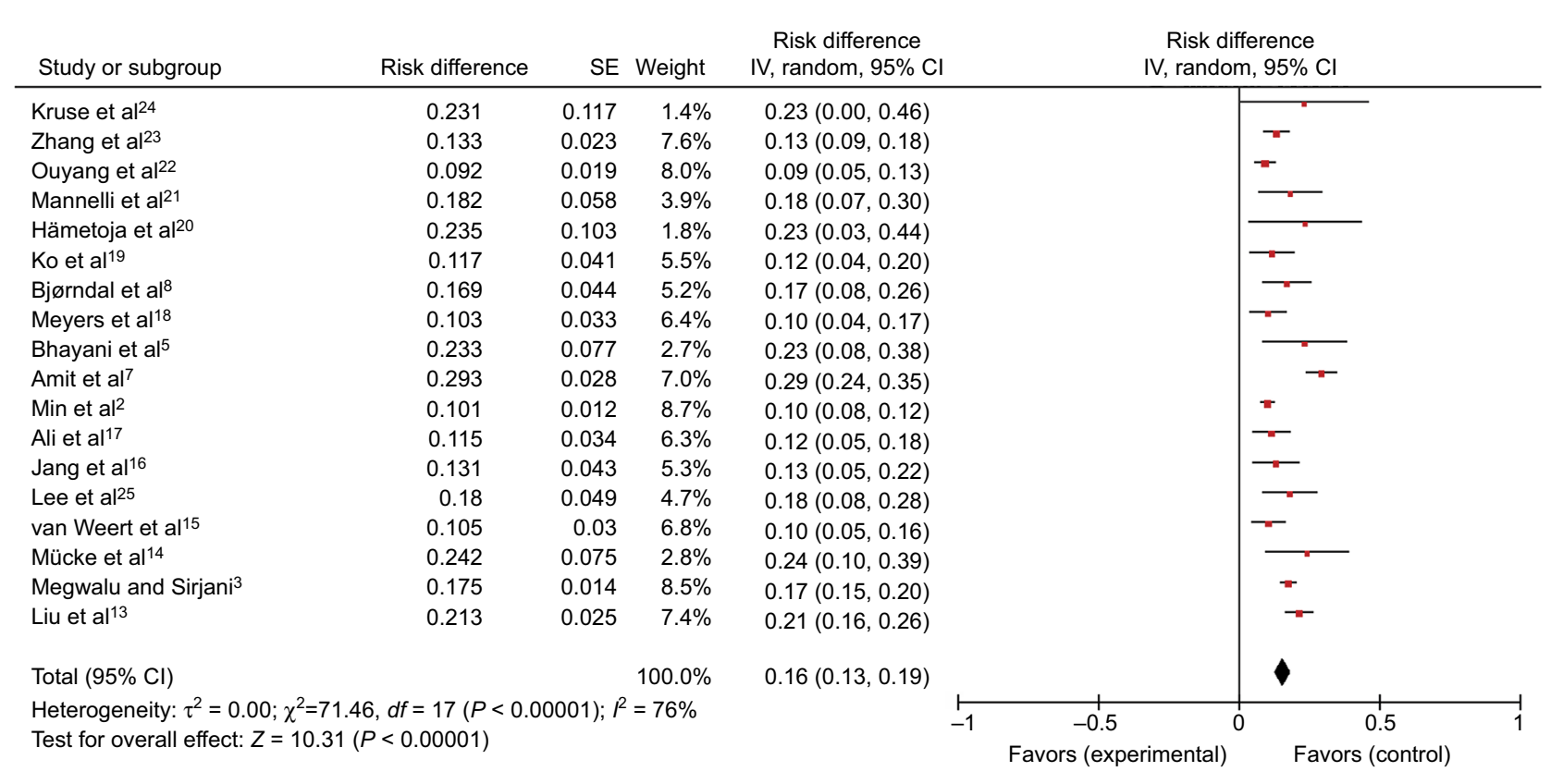

Figure 2 Overall cervical metastases rate.

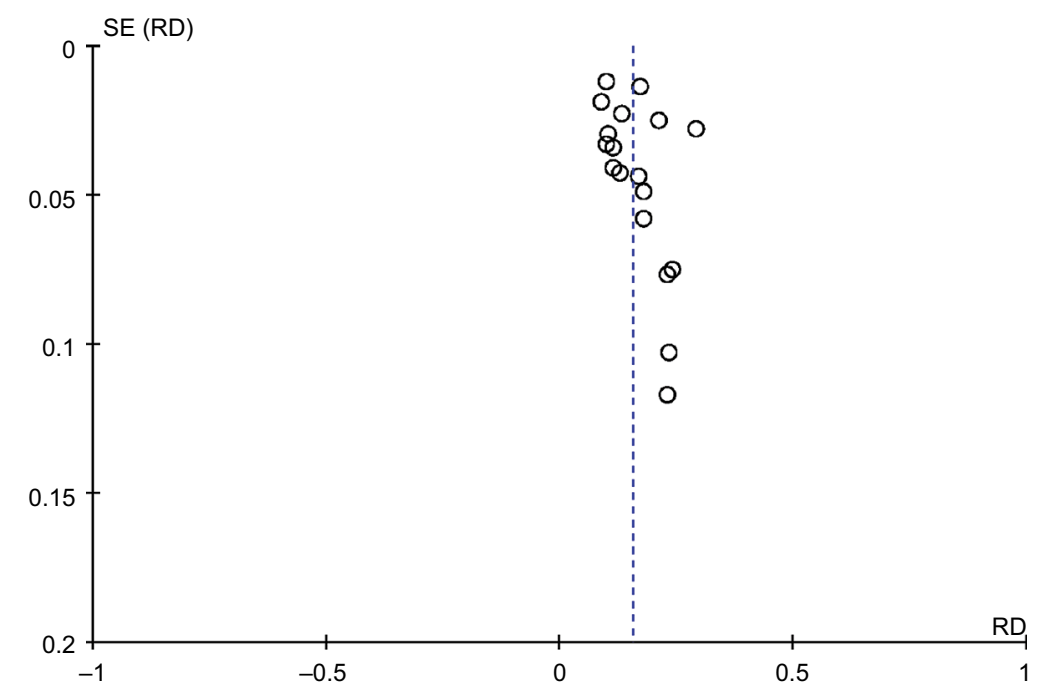

Figure 3 Funnel plot of overall metastases rate.

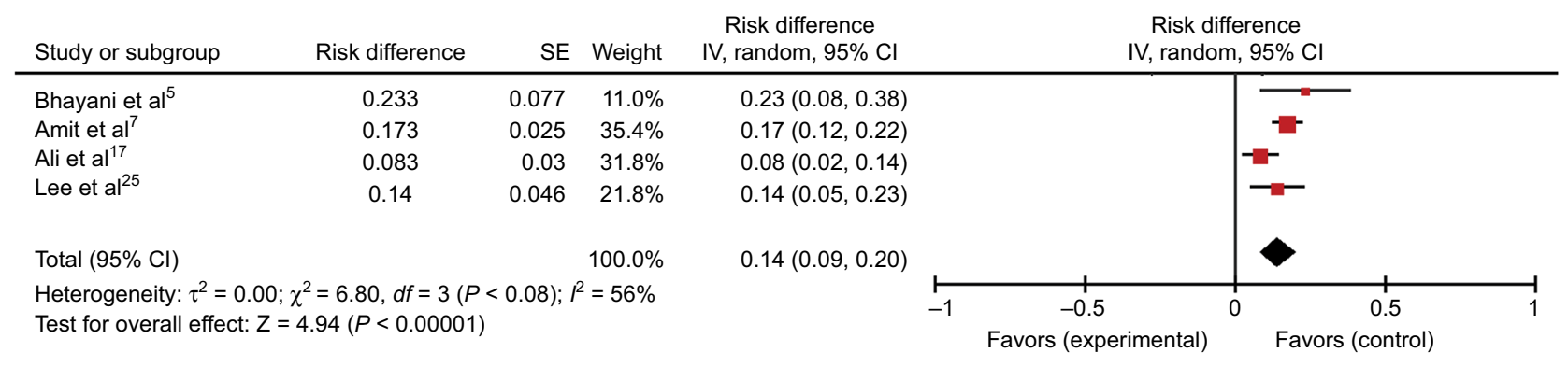

Figure 4 Cervical lymph node occult metastases rate. 


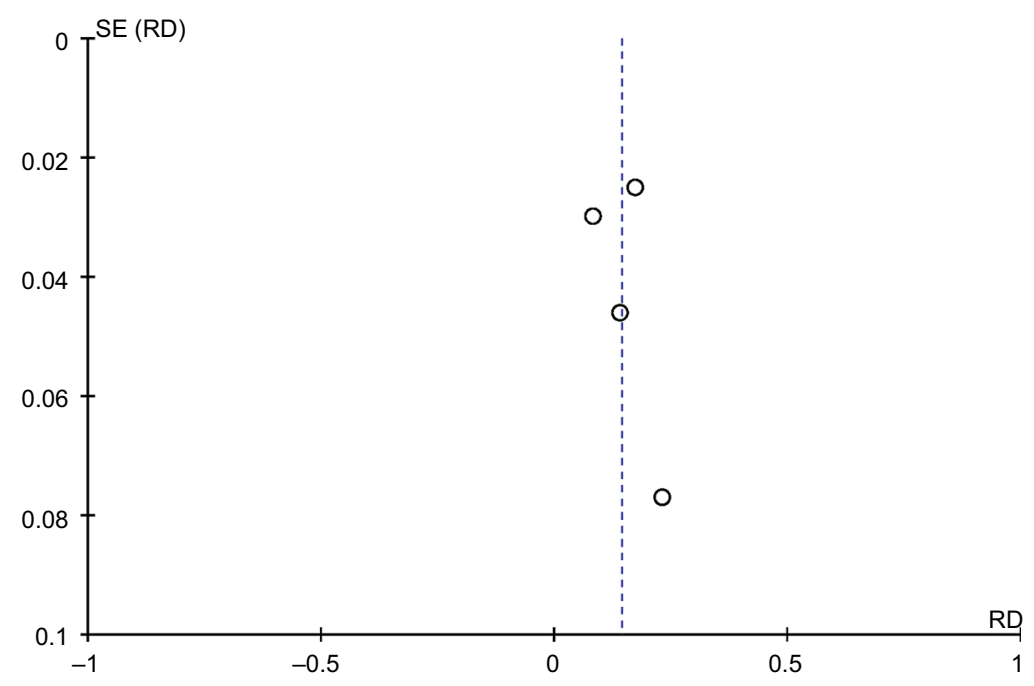

Figure 5 Funnel plot of occult metastases rate.

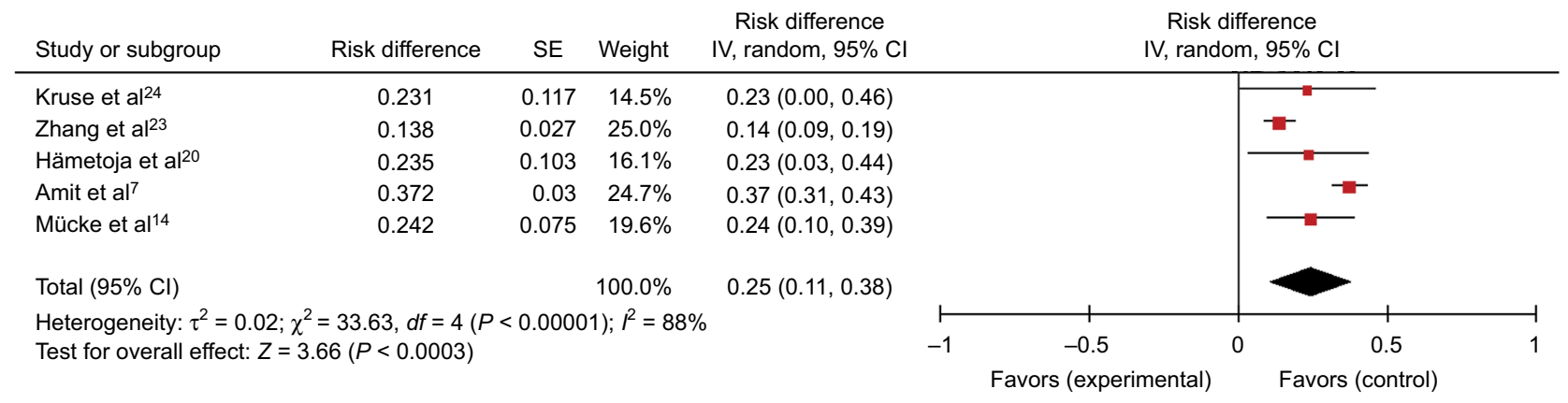

Figure 6 Metastases rate of ACC of MiSGs.

Abbreviations: ACC, adenoid cystic carcinoma; MiSGs, minor salivary glands.

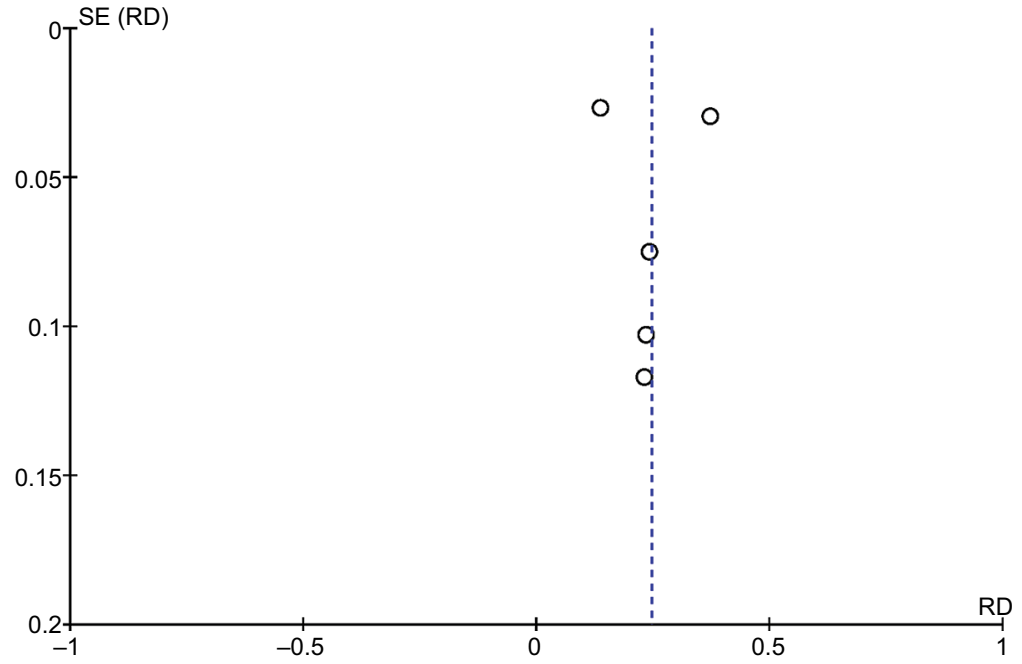

Figure 7 Funnel plot of metastases rate of ACC of MiSGs.

Abbreviations: ACC, adenoid cystic carcinoma; MiSGs, minor salivary glands. 


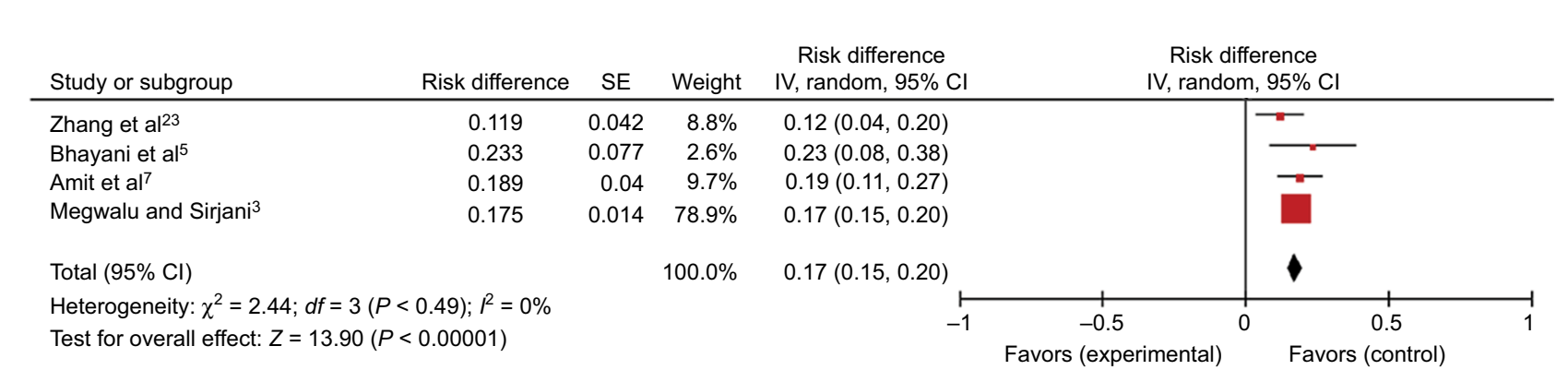

Figure 8 Metastases rate of ACC of MaSGs.

Abbreviations: ACC, adenoid cystic carcinoma; MaSGs, major salivary glands.

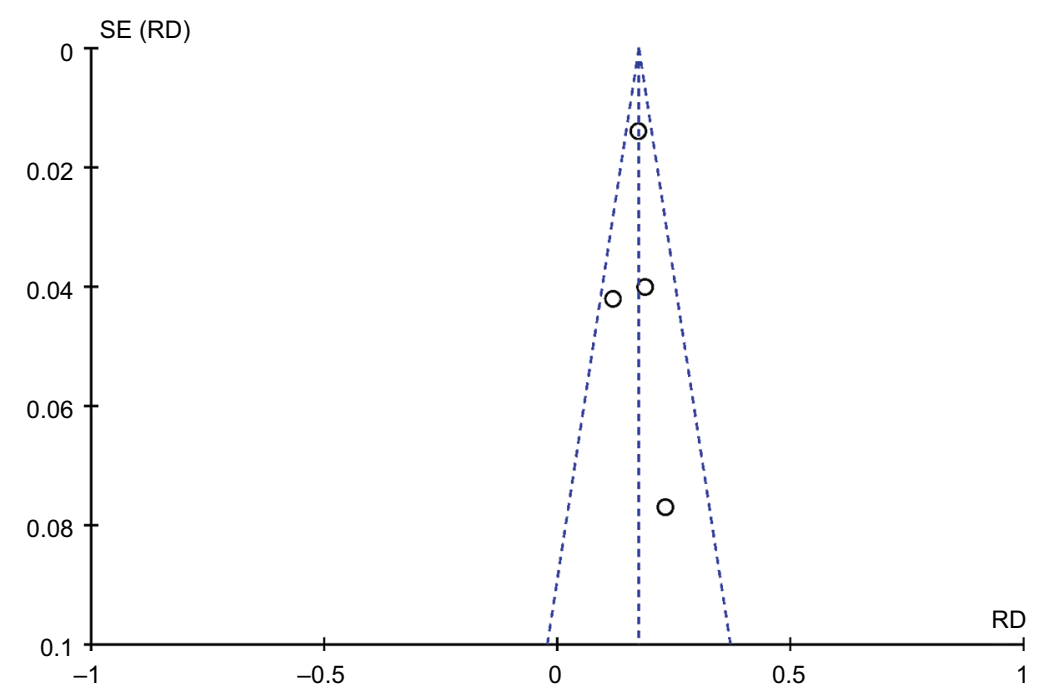

Figure 9 Funnel plot of metastases rate of ACC of MaSGs.

Abbreviations: ACC, adenoid cystic carcinoma; MaSGs, major salivary glands.

fixed effects model (Figure 8). The corresponding Funnel plots indicated that there was no publication bias in these 4 researches (Figure 9).

\section{Sensitivity analysis}

Sensitivity analyses were carried out by deleting the data in the largest and minimum weight, respectively, to evaluate the stability of this meta-analysis. The merge frequency cervical lymph node overall metastases rate was $16 \%(95 \%$ CI: 13-19). The result was $16 \%$ (95\% CI: 13-19), while the data in the largest weight ${ }^{2}$ were deleted. When the data in the minimum weight ${ }^{24}$ were removed, the result was $16 \%$ (95\% CI: 13-19). Deleting the data of largest or minimum weight had a negligible influence, which indicated that the results were generally stable.

\section{Discussion}

ACC of the head and neck is an uncommon carcinoma; treatment includes surgery with or without adjuvant radiotherapy. The presence of cervical lymph node metastases has shown to be a common cause of treatment failure in patients with ACC of the head and neck. ${ }^{27}$ Cervical lymph node metastasis has traditionally been regarded as a obviously uncommon occurrence. However, treatment of the neck is still debatable with ACC of head and neck as the reported incidence of lymph node metastasis varies widely, from $4 \%$ to $33 \% .^{4-7}$ Therapeutic neck dissection is usually performed in $\mathrm{cN}+$ status. But for patients with clinically node negative $(\mathrm{cN}-)$ status, it is uncertain whether to perform END. Amit et al reported an overall nodal metastases rate of $29.3 \%$ ( 79 of 270 patients) and an occult metastases incidence of $17.3 \%$ (39 of 226 patients) and suggested that elective neck treatment should be considered. ${ }^{7}$ Nobis et al strongly advised END for all patients with ACC because of the high rate (43.8\%) of lymphogenic metastases for postoperative examination. ${ }^{28}$ Lee et al concluded that END itself was not beneficial for survival or distant metastases but can provide valuable staging and prognostic information in ACC; in this reach, the overall nodal metastases rate was $18 \%$ ( 11 of 61 patients) and the occult metastases rate was $14 \%$ ( 8 of 57 patients). ${ }^{25}$ On 
the other hand, Cao et al reported a nodal metastases rate of $7.9 \%$, and in their opinions, selective neck dissection should be performed for patients who were found to have lymph node metastases by clinical or imaging. ${ }^{29}$ Min et al advised that selective neck dissection should be considered in ACC of minor salivary glands as MiSGs have a higher ratio of lymph node metastases than MaSGs. ${ }^{2}$

In this research, we retrieved 18 articles about node metastases of ACC, and the overall metastases ratio of metaanalysis was $16 \%$, which was lower than the metastatic risk of squamous cell carcinoma of head and neck. ${ }^{30-33}$ Pitman considered that for patients of head and neck squamous cell carcinoma, an END should be performed if the probability of occult cervical metastases are higher than $15-20 \% .{ }^{34}$ Amit et al recommended END for patients with ACC when occult cervical metastases are higher than $15-20 \%$, as practiced for those with squamous cell carcinoma. ${ }^{7}$ However, in this research, the pooled rate of occult cervical metastases is $14 \%$, which is slightly lower than the standard rate (15-20\% rate of occult cervical metastases) of END for head and neck squamous cell carcinoma. Thus, we suggest that neck dissection might not be always necessary for all patients with ACC of the head and neck to avoid complications such as postoperative shoulder disability and scar. But for patients without neck dissection, routine imaging methods such as neck ultrasonography and MRI should be considered for follow-up diagnosis; furthermore, period of follow-up should be shortened.

In our research, the tumor primary sites had been analyzed and the pooled metastases rates were $25 \%$ and $17 \%$ for ACC of MiSGs and MaSGs, respectively. The results are similar to those of Hämetoja et $\mathrm{al}^{20}$ and Megwalu and Sirjani. ${ }^{3}$ Besides, Min et al studied 616 cases of head and neck ACC, identifying $62(10 \%)$ cases of ACC with cervical lymph node metastasis. In those cases, primary tumor sites involving the base of tongue, mobile tongue and mouth floor were the highest incidences of cervical lymph nodes metastasis. ${ }^{2}$ Similarly, in the study of Zhang et al, the reported incidence of cervical metastases was higher when primary tumor sites were situated at the mouth floor, sublingual and tongue. ${ }^{23}$ These researches provide some favorable evidence for us. Despite this article lacking occult metastasis data, the overall metastases rate of MiSGs up to $25 \%$ is enough to attract our attention. Amit et al found that END is not associated with outcome of patients. But for patients with ACC of the oral cavity, their findings supported the consideration of elective neck treatment., ${ }^{7,35}$ Lee et al observed that regional recurrence was identified in 4 patients with stage $\mathrm{cN} 0$ who did not undergo END, and in their opinion, proper therapeutic and END can achieve favorable regional control. ${ }^{25}$ END could remove occult regional disease and provide a regional recurrence-free life for patients with ACC. In addition, END could provide valuable staging and prognostic information in ACC. Therefore, we suggest that patients with ACC of MiSGs especially involving the mouth floor, base of tongue, mobile tongue might perform neck dissection, which agreed with the opinions of Min et $\mathrm{al}^{2}$ and Zhang et al. ${ }^{23}$

There are a few articles on the correlation between END and prognosis of ACC in the head and neck; there have been no randomized controlled trials either. The existence of heterogeneity in this meta-analysis may relate to the quantity, quality and type of these articles. The quantity of researches about occult metastases is less. There are not enough data and articles about the relationship between histology or tumor growth patterns and nodal metastases for the meta-analysis. Most of the articles contained in this analysis are retrospective studies and even some with small sample sizes. Thus, more prospective studies or random clinical trials with larger sample sizes are expected in the future.

\section{Conclusion}

Lymphatic spread is generally less frequent with ACC than with mucosal squamous cell carcinoma. Pooled frequency of cervical lymph node occult metastases was 14\% (95\% CI: 9-20), which was slightly lower than the standard (15-20\% rate of occult cervical metastases) for END for head and neck squamous cell carcinoma. Thus, END is unnecessary for all patients with salivary gland ACC of head and neck. Careful follow-up of cervical lymph node status is important, and the period of follow-up should be shortened. Moreover, compared with major salivary glands, minor salivary glands have a higher cervical lymph node metastases rate in ACC. The overall cervical lymph node metastases rate of MiSGs up to $25 \%$ is enough to attract our attention. Therefore, we suggest that neck dissection might be applied to ACC of minor salivary glands.

\section{Disclosure}

The authors report no conflicts of interest in this work.

\section{References}

1. Shen C, Xu T, Huang C, Hu C, He S. Treatment outcomes and prognostic features in adenoid cystic carcinoma originated from the head and neck. Oral Oncol. 2012;48(5):445-449.

2. Min R, Siyi L, Wenjun Y, et al. Salivary gland adenoid cystic carcinoma with cervical lymph node metastasis: a preliminary study of 62 cases. Int J Oral Maxillofac Surg. 2012;41(8):952-957. 
3. Megwalu UC, Sirjani D. Risk of nodal metastasis in major salivary gland adenoid cystic carcinoma. Otolaryngol Head Neck Surg. 2017;156(4):660-664.

4. Lloyd S, Yu JB, Wilson LD, Decker RH. Determinants and patterns of survival in adenoid cystic carcinoma of the head and neck, including an analysis of adjuvant radiation therapy. Am J Clin Oncol. 2011;34(1):76-81.

5. Bhayani MK, Yener M, El-Naggar A, et al. Prognosis and risk factors for early-stage adenoid cystic carcinoma of the major salivary glands. Cancer. 2012;118(11):2872-2878.

6. Armstrong JG, Harrison LB, Thaler HT, et al. The indications for elective treatment of the neck in cancer of the major salivary glands. Cancer. 1992;69(3):615-619.

7. Amit M, Binenbaum Y, Sharma K, et al. Incidence of cervical lymph node metastasis and its association with outcomes in patients with adenoid cystic carcinoma. An international collaborative study. Head Neck. 2015;37(7):1032-1037.

8. Bjørndal K, Krogdahl A, Therkildsen MH, et al. Salivary adenoid cystic carcinoma in Denmark 1990-2005: outcome and independent prognostic factors including the benefit of radiotherapy. Results of the Danish Head and Neck Cancer Group (DAHANCA). Oral Oncol. 2015;51(12):1138-1142.

9. DeAngelis AF, Tsui A, Wiesenfeld D, Chandu A. Outcomes of patients with adenoid cystic carcinoma of the minor salivary glands. Int J Oral Maxillofac Surg. 2011;40(7):710-714.

10. Fordice J, Kershaw C, El-Naggar A, Goepfert H. Adenoid cystic carcinoma of the head and neck: predictors of morbidity and mortality. Arch Otolaryngol Head Neck Surg. 1999;125(2):149-152.

11. Spiro RH. Distant metastasis in adenoid cystic carcinoma of salivary origin. Am J Surg. 1997;174(5):495-498.

12. Gomez DR, Hoppe BS, Wolden SL, et al. Outcomes and prognostic variables in adenoid cystic carcinoma of the head and neck: a recent experience. Int J Radiat Oncol Biol Phys. 2008;70(5):1365-1372.

13. Liu Z, Fang Z, Dai T, Zhang C, Sun J, He Y. Higher positive lymph node ratio indicates poorer distant metastasis-free survival in adenoid cystic carcinoma patients with nodal involvement. J Craniomaxillofac Surg. 2015;43(6):751-757.

14. Mücke T, Tannapfel A, Kesting MR, et al. Adenoid cystic carcinomas of minor salivary glands. Auris Nasus Larynx. 2010;37(5):615-620.

15. van Weert S, Bloemena E, van der Waal I, et al. Adenoid cystic carcinoma of the head and neck: a single-center analysis of 105 consecutive cases over a 30-year period. Oral Oncol. 2013;49(8):824-829.

16. Jang S, Patel PN, Kimple RJ, McCulloch TM. Clinical outcomes and prognostic factors of adenoid cystic carcinoma of the head and neck. Anticancer Res. 2017;37(6):3045-3052.

17. Ali S, Palmer FL, Katabi N, et al. Long-term local control rates of patients with adenoid cystic carcinoma of the head and neck managed by surgery and postoperative radiation. Laryngoscope. 2017;127(10):2265-2269.

18. Meyers M, Granger B, Herman P, et al; REFCOR members. Head and neck adenoid cystic carcinoma: a prospective multicenter REFCOR study of 95 cases. Eur Ann Otorhinolaryngol Head Neck Dis. 2016;133(1):13-17.

19. Ko JJ, Siever JE, Hao D, Simpson R, Lau HY. Adenoid cystic carcinoma of head and neck: clinical predictors of outcome from a Canadian centre. Curr Oncol. 2016;23(1):26-33.
20. Hämetoja H, Hirvonen K, Hagström J, et al. Early stage minor salivary gland adenoid cystic carcinoma has favourable prognosis. Virchows Arch. 2017;471(6):785-792.

21. Mannelli G, Cecconi L, Fasolati M, Santoro R, Franchi A, Gallo O. Parotid adenoid cystic carcinoma: retrospective single institute analysis. Am J Otolaryngol. 2017;38(4):394-400.

22. Ouyang DQ, Liang LZ, Zheng GS, et al. Risk factors and prognosis for salivary gland adenoid cystic carcinoma in southern china: a 25 -year retrospective study. Medicine (Baltimore). 2017;96(5):e5964.

23. Zhang CY, Xia RH, Han J, et al. Adenoid cystic carcinoma of the head and neck: clinicopathologic analysis of 218 cases in a Chinese population. Oral Surg Oral Med Oral Pathol Oral Radiol. 2013;115(3):368-375.

24. Kruse AL, Grätz KW, Obwegeser JA, Lübbers HT. Malignant minor salivary gland tumors: a retrospective study of 27 cases. Oral Maxillofac Surg. 2010;14(4):203-209.

25. Lee SY, Kim BH, Choi EC. Nineteen-year oncologic outcomes and the benefit of elective neck dissection in salivary gland adenoid cystic carcinoma. Head Neck. 2014;36(12):1796-1801.

26. Zhang WB, Peng X. Cervical metastases of oral maxillary squamous cell carcinoma: a systematic review and meta-analysis. Head Neck. 2016;38 Suppl 1:E2335-E2342.

27. Terhaard CH, Lubsen H, Van der Tweel I, et al; Dutch Head and Neck Oncology Cooperative Group. Salivary gland carcinoma: independent prognostic factors for locoregional control, distant metastases, and overall survival: results of the Dutch head and neck oncology cooperative group. Head Neck. 2004;26(8):681-692; discussion 692-693.

28. Nobis CP, Rohleder NH, Wolff KD, Wagenpfeil S, Scherer EQ, Kesting MR. Head and neck salivary gland carcinomas-elective neck dissection, yes or no? J Oral Maxillofac Surg. 2014;72(1):205-210.

29. Cao C, Ge M, Chen X, Xu J, Chen C. Clinical outcomes and prognostic factors of salivary gland adenoid cystic carcinomas: a case control study. Oral Surg Oral Med Oral Pathol Oral Radiol. 2017;123(5):531-535.

30. Tao L, Lefèvre M, Callard P, Périé S, Bernaudin JF, St Guily JL. Reappraisal of metastatic lymph node topography in head and neck squamous cell carcinomas. Otolaryngol Head Neck Surg. 2006;135(3) :445-450.

31. Khafif A, Lopez-Garza JR, Medina JE. Is dissection of level IV necessary in patients with T1-T3 N0 tongue cancer? Laryngoscope. 2001;111(6):1088-1090.

32. Woolgar JA. Histological distribution of cervical lymph node metastases from intraoral/oropharyngeal squamous cell carcinomas. Br J Oral Maxillofac Surg. 1999;37(3):175-180.

33. Byers RM, Weber RS, Andrews T, McGill D, Kare R, Wolf P. Frequency and therapeutic implications of "skip metastases" in the neck from squamous carcinoma of the oral tongue. Head Neck. 1997;19(1): 14-19.

34. Pitman KT. Rationale for elective neck dissection. Am J Otolaryngol. 2000;21(1):31-37.

35. Amit M, Na'ara S, Sharma K, et al. Elective neck dissection in patients with head and neck adenoid cystic carcinoma: an international collaborative study. Ann Surg Oncol. 2015;22(4):1353-1359.
Cancer Management and Research

\section{Publish your work in this journal}

Cancer Management and Research is an international, peer-reviewed open access journal focusing on cancer research and the optimal use of preventative and integrated treatment interventions to achieve improved outcomes, enhanced survival and quality of life for the cancer patient. The manuscript management system is completely online and includes

\section{Dovepress}

a very quick and fair peer-review system, which is all easy to use. Visit http://www.dovepress.com/testimonials.php to read real quotes from published authors. 